\title{
EXTERNAL KINK MODES AS A MODEL FOR MHD ACTIVITY ASSOCIATED WITH ELMS
}

BY

J. MANICKAM

January 1992

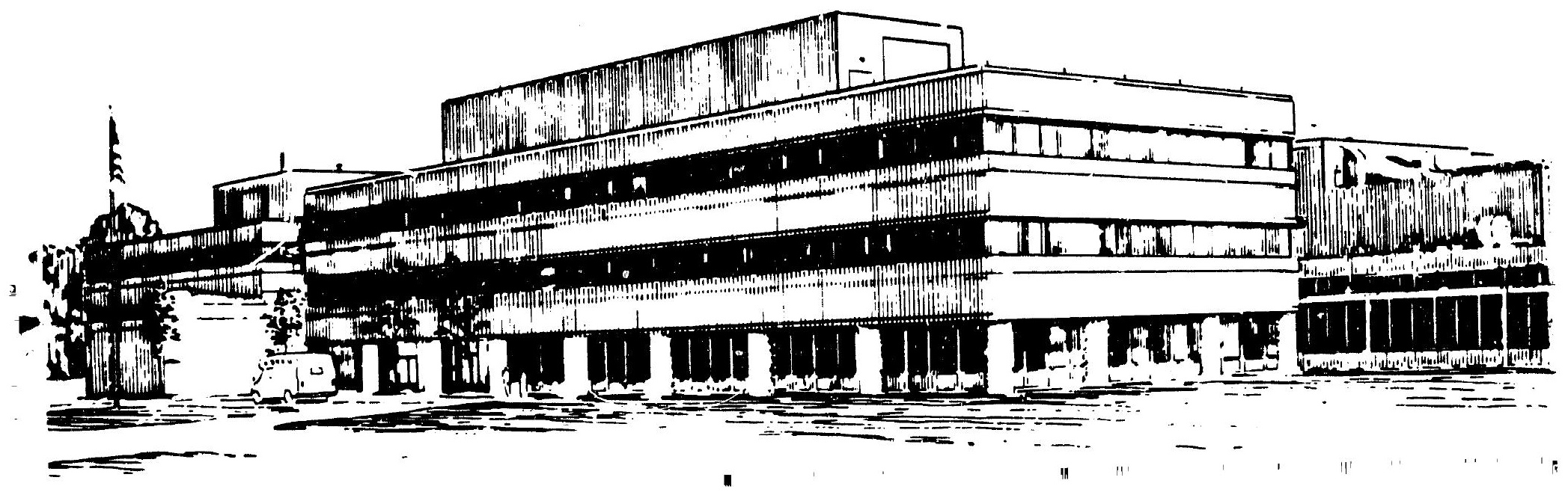




\section{NOTICE}

This report was prepared as an account of work sponsored by an agency of the United States Government. Neither the United States Government nor any agency thereof, nor any of their employees, makes any warranty, express or implied, or assumes any legal liability or responsibility for the accuracy, completeness, or usefulness of any information, apparatus, product, or process disclosed, or represents that its use would not infringe privately owned rights. Reference herein to any specific commercial produce, process, or service by trade name, trademark, manufacturer, or otherwise, does not necessarily constitute or imply its endorsement, recommendation, or favoring by the United States Government or any agency thereof. The views and opinions of authors expressed herein do not necessarily state or reflect those of the United States Government or any agency thereof.

\section{NOTICE}

This report has been reproduced directly from the best available copy.

Available to DOE and DOE contractors from the:

Office of Scientific and Technical Information

P.O. Box 62

Oak Ridge, TN 37831 ;

Prices available from (615) 576-8401.

Available to the public from the:

National Technical Information Service

U.S. Department of Commerce

5285 Port Royal Road

Springfield, Virginia 22161

703-487-4650 


\title{
External kink modes as a model for MHD activity associated with ELMs
}

\author{
J. Manickam \\ Princeton Plasma Physcis Laboratory \\ Princeton NJ 08543
}

\begin{abstract}
Tokamak plasmas in the high confinement mode of operation are known to exhibit edge localized activity referred to as ELMs. A model is proposed for the underlying cause in terms of the external kink mode. The build up of the current density near the plasma edge is shown to decrease the shear in the safety-factor, $q$, profile and lead to destabilisation of the kink mode. The role of the plasma geometry and equilibrium profiles is discussed.
\end{abstract}




\section{Introduction}

Tokamak plasmas entering the high confinement mode, $\mathrm{H}$-mode, of operation $^{1-6}$ experience a sudden decrease in the $D_{\alpha}$ emission and a sharp rise in the electron temperature and/or density, $\left(T_{\varepsilon} / n_{e}\right)$, near the plasma edge. Subsequently, the plasma may exhibit edge localized activity, dubbed as Edge Localized Modes (ELMs), which limit any further increases in $T_{e}$ or $n_{e}$. The principal features of ELMs are, a burst of MHD activity associated with an increase in the $D_{\alpha}$ emission, increased edge recycling and additional loss of particles and energy. These losses can sometimes extend to the core of the plasma. Since the ELMs are associated with a degradation of the plasma, it would be useful to understand the underlying physics, in order to devise methods to avoid them. Previous studies have focussed on different MHD instabilities as the probable cause. Gohill et. al..$^{7}$ have suggested that some giant ELMs in DIII-D may be due to ballooning modes, while Ohyabu et. al. ${ }^{8}$ have speculated on the role of microtearing modes. More recently, Kaye et. al. ${ }^{9}$ have identified the observed MHD precursor on PBX-M as being an ideal pressure driven kink mode. This, in association with the observation of von Goeler et. al. ${ }^{10}$ and Toi et. al. ${ }^{11}$ that they observe a helical mode with $m / n=3 / 1$ or $4 / 1$, where $m$ and $n$ are the poloidal and toroidal mode numbers respectively, suggests that the external kink mode is indeed a strong candidate for the MHD activity associated with ELMs.

For the kink mode to serve as a model for ELMs, it is necessary to show that the instability depends on the details of the plasma profiles near the edge in such a manner that it can account for the observed phenomonology.

The external kink mode is generally considered to be a current driven mode, often dominated by a single helicity such that $m / n>q_{\text {edge }}$, where $m$ and $n$ are the poloidal and toroidal mode numbers respectively. The shear in the safety-factor, $q$, profile is a stabilizing factor and finite edge-current is destabilizing. The instability is also sensitive to the location of the closest rational surface to the plasma in the vacuum region. In particular when the rational surface is very close to the plasma, e.g., $q_{\text {edge }} \sim 2.95$, the resulting instability is strongly localised near the plasma edge and is termed a peeling mode ${ }^{12}$. As $q_{\text {edge }}$ is reduced the instability has a greater radial distribution, and the growth-rate decreases until $q_{\text {edge }}$ crosses the next rational value, when the peeling mode reappears. 
This simple characterization of the instability is strongly influenced by details of the tokamak geometry and plasma profiles. For instance, if the aspectratio is reduced and the plasma cross-section is strongly non-circular, then there is stronger poloidal coupling and several harmonics may be present. The plasma pressure profile and the proximity to a $\beta$ limit can also strongly influence the mode. In this case it may be more appropriate to refer to it as a pressure driven kink mode. If $q_{\text {axis }}<1$, there is the additional possibility of coupling the dominant external harmonic to an internal harmonic such as the $m=1$, in which case the instability would have a much stronger effect on the plasma.

In this paper we will show the dependence of the kink mode on the plasma parameters, with special emphasis on the details of the current profile near the plasma edge. We will then make the case for this instability to be the underlying cause of ELMs.

The outline of this paper is as follows; we present the theoretical model for the plasma profiles which will allow us to control all the principal features of the $q$ or current profiles. Then we discuss the results obtained in a simple geometry, (large aspect-ratio, circular) at zero $\beta$. The emphasis here will be to elucidate the relationship between the current profile and the q-profile on the one hand with the stability to the external kink mode. This is followed by a brief consideration of the role of finite aspect ratio and non-circular cross-sections. Finally we consider the effect of finite $\beta$ on the kink mode. In the final section we present a discussion of the results in the context of ELMs.

\section{Theoretical model}

The main emphasis of this work is to show the relationship between equilibrium plasma parameters and the stability to external kink modes. In order to emphasize the role of the current profile, we start with a simple geometry; circular cross-section and large aspect-ratio, $\mathrm{R} / \mathrm{a}=10$. The pressure is set to be zero, so that any observed instability will be purely current driven. The aim is to obtain equilibria with specific edge current properties and then study their low-n ideal MHD stability using the PEST code. ${ }^{13}$ In order to get the maximum control over the current profile, it is useful to introduce a multi-parameter formula for defining the toroidal stream function $g$, which 
appears in the Grad-Shafranov equation:

$$
x \frac{\partial}{\partial x} \frac{1}{x} \frac{\partial \Psi}{\partial x}+\frac{\partial^{2} \Psi}{\partial z^{2}}=2 \pi x J_{\Phi}
$$

where

$$
J_{\Phi}=-2 \pi\left(x \frac{d p}{d \Psi}+B_{0}^{2} R_{0}^{2} g \frac{d g}{d \Psi}\right)
$$

where $R_{0}$ is a normalizing scale length chosen such that the toroidal field is given by, $B_{\Phi}=B_{0} R_{0} g \nabla \Phi$. The function $g$ is defined through the expression:

$$
g=1-g p\left[(1-\psi)^{\mathrm{GBETA}}-g p 0\left(1-\psi^{\mathrm{GBETA} 3}\right)^{\mathrm{GBETA} 2}-g p 1 \psi^{\mathrm{GBETA} 4}\right]
$$

where GBETA, GBETA2, GBETA3, GBETA4, $g p 0$ and $g p 1$ are input quantities and $g p$ is adjusted within the code to set the total current and hence the $q_{\text {edge. }}$. The variable $\psi$ is a normalized flux label which has the value, $0 \leq \psi \leq 1$, when measured from the magnetic axis to the plasma edge. In general $g p 0$ and GBETA are adjusted to set $q_{\text {axis }}$ and the other parameters are used to tailor the current near the plasma edge.

Figure 1 shows an example of the ability to tailor the current profile. The $\Leftarrow$ three sets of curves in Figure la show the surface averaged current, $\langle J \cdot B\rangle$, and $1 \mathrm{~b}$ the corresponding $q$-profiles for three sets of input data. The input has been adjusted so that the three equilibria have differerent values of $q_{\text {edge }}^{\prime}$ but have approximately the same values of $q_{\text {axis }}(\approx 1.05), q_{\text {edge }}(=2.95)$ and $J_{\text {edge }} / J_{\text {axis }}(\approx 0.06)$. This ability to tailor the currrent profile can be used to selectively vary any one of the current parameters, while holding the others approximately constant. With this procedure we hope to identify the role of each of the principal current profile features in determining the kink mode stability properties.

As indicated earlier the PEST code is used to analyse these equilibria to determine their stability to the external kink mode, with $n=1$ and boundary conditions corresponding to a wall at infinity. When a current-driven external kink instability is found, it is generally characterized by a displacement which peaks near the plasma edge. A fourier decomposition of the radial component of the displacement vector reveals that it is often dominated by a single poloidal harmonic whose mode number $m$ is determined by $q_{\text {edge }}$, such that $m$ is the first integer greater that $q_{\text {edge }}$. Thus, for the equilibria of figure 
1 , this would be $m=3$, since $q_{\text {edge }}=2.95$. A typical instability is shown $\Leftarrow$ in figure $2 ; 2$ a shows the fourier decomposition of the radial component of $\Leftarrow$ the displacement vector, $\xi_{\Psi}$, while $2 \mathrm{~b}$ shows the projection of the vector onto the $x-z$ plane at an arbitrary toroidal angle. The particular form of the instability is dependent on several parameters, notably, $q_{\text {edge, }}$ geometry (ie. non-circularity and aspect-ratio), as well as the plasma pressure. In general when $q_{\text {edge }}$ is close to an integer, as in the preceeding example ( 2.95 ), the instability will have a structure typical of the peeling mode a mode confined to the plama edge. As $q_{\text {edge }}$ is reduced the mode growth-rate generally increases and its structure extends deeper within the plasma. An example of this is shown in Figure 3. As before 3a shows the radial structure $\Leftarrow$ of the fourier compnents and $3 \mathrm{~b}$ the projection of the displacement vector. The latter clearly indicates the increased radial penetration of the instability. The instability shown in figures 2 and 3, were observed in a tokamkak with $a \Leftarrow$ large aspect-ratio $(=10)$, and a circular cross-section. The principal effect of changing these the geometric parameters is to modify the coupling to satellite fourier harmonics, which generally increases as the aspect-ratio is decreased or the plasma non-circularity is increased. This effect is enhanced as the plasma pressure increases.

The role of plasma-pressure in modulating the kink instability is more complicated. Depending on the exact details of the pressure profile, the instability may couple strongly to the inside, especially if the plasma is close to the high- $n$ ballooning limit. An example of such a pressure driven kink is shown in Figure 4 for an equilibrium near marginal stability with $\beta=$ $0.4 \%(\beta /(I / a B)=2.2)$. Note that the external $m=3$ harmonic is strongly coupled to the internal $m=2$ harmonic, and other harmonics play a lesser role.

In this situation it becomes difficult to distinguish between pressure- and current-driven kink modes. A common practice is to place a conducting shell at the plasma edge, and any instability that remains is considered pressure driven, while instabilites which require free boundary conditions are considered to be external kink modes. There are however grey areas where these distinctions are hard to resolve and other considerations will have to be invoked. 


\section{Results}

\section{A. Circular cross-section, zero $\beta$.}

We start by first considering the simplest scenario, where $q_{\text {axis }}$ and $q_{\text {edge }}$ are held constant, and the detailed structure of the current profile near the edge is varied. This variation will include keeping the edge current, $J_{\text {edge }} / J_{\text {axis }}$ fixed and varying the shear in the $q$-profile. We will then fix $J_{\text {edge }} / J_{\text {axis }}$ at a different value and repeat the exercise. In both cases the aim will be to determine the critical $q^{\prime}$ which stabilizes the kink mode. The results are shown in figure 5 , which plots the square of the growth-rate, $\left(\omega^{2}\right)$, for the kink mode against $q^{\prime}$, for three different values of $J_{\text {edge }} / J_{\text {axis }}=0.0,0.038$ and 0.055 . In each case we observe that as $q^{\prime}$ increases $\omega^{2}$ decreases and stability is reached when $q^{\prime}$ exceeds a critical value. We compare this critical value $q_{\mathrm{c}}^{\prime}$ for these and other values of $J_{\text {edge }} / J_{\text {axis }}$ in figure 6 . We note that even with $J_{\text {edge }} / J_{\text {axis }}=.010$, which represents a parallel current at the edge which is $10 \%$ of the current at the plasma center, a modest increase of $q^{\prime}$ can stabilize the kink mode. Conversely, we note that if $q^{\prime} \leq 4.9$ that no modification of $J_{\text {edge }} / J_{\text {axis }}$ can stabilize the mode.

As noted earlier, there are several parameters which affect the kink stability properties. We now address another of them, ie. $q_{\text {edge. To facilitate }}$ the discussion we introduce the quantity, $\Delta q \equiv q_{\text {integer }}-q_{\text {edge }}$, such that $0 \leq \Delta q \leq 1$. When $\Delta q$ is small and finite the rational surface lies in the vacuum close to the plasma. As $\Delta q$ increases the rational surface moves further away from the plasma edge. In this section we shall keep $J_{\text {edge }}$ fixed and equal to zero, recognizing that these results can be extrapolated to nonzero $J_{\text {edge }}$ using the previous results where $q_{\text {edge }}$ was kept fixed. As before we fix $q_{\text {axis }} \approx 1.05$ and vary $q_{\text {edge }}$, and at each value of $q_{\text {edge }}$ we modify $q^{\prime}$ to determine the marginal value, $q_{\mathrm{c}}^{\prime}$. The results are shown in figure 6 in the range $2 \leq q \leq 4$. Two important features are worth noting here; a) as $q_{\text {edge }}$ is decreased and $\Delta q$ increases, the value of $q_{c}^{\prime}$ decreases and b) there is a stable gap for $q_{\text {edge }}$ slightly greater than an integer, $\Delta q<<1$. This latter result is well known, but the first conclusion is new. A secondary feature of these results is that at higher values of $q_{\text {edge }}$, the required shear to stabilize the kink mode increases. Care must be taken in interpreting this result. On face value this would seem to suggest that the higher $q_{\text {eage }}$ cases are more unstable. In fact the higher the $q_{\text {edge }}$ the easier it is to get a larger $q^{\prime}$, as a 
simple examination of the $q$-profile would reveal.

Recognizing that $q^{\prime}$ is a difficult quantity to assess from an experiment, we examine the plasma profiles to find an equivalent quantity. This is found to be the current in the outer regions of the plasma, defined as the current beyond a particular flux surface specified as a fraction of the total current,eg. $I(90) \equiv 1-I$ (within the $90 \%$ flux surface) $/ I$ (Total). Figure 8 shows the relationship between $q^{\prime}$ and $I(90)$ as a scatter plot. Several different plasma conditions are included in this plot, $i e$. different $q_{\text {edge }}, J_{\text {edge }}$ etc. We observe an inverse linear corelation between the two quantities. This provides us with the confidence to replot the stability diagram of figure 7 , in figure 9 , which shows the threshold $I(90)$ above which instability sets in as $q_{\text {edge }}$ is varied. Here we start to see a possible connection between the kink mode and ELMs in a $\mathrm{H}$-mode regime plasma. A plasma in the $\mathrm{H}$-mode is known to have a temperature pedestal near the plasma edge, this in turn is expected to cause a pedestal in the plasma current. The finite current there would effectively increase $I(90)$ resulting in a lowered shear, $q^{\prime}$, which can then destabilize the external kink mode. It should be noted here that the implied stability thresholds in terms of $q^{\prime}$ and $I(90)$ are particular for the specific model profiles assumed. The qualitative nature of these results will carry over to other plasma geometries and profiles, however the exact quantitative thresholds will have to be determined anew for the specific geometry and profiles of interest.

\section{B. Geometric efects, zero $\beta$}

We now discuss the consequences of changing the geometry. As before we set $\beta=0, q_{\mathrm{axis}} \approx 1.05$ and $q_{\mathrm{edge}}=2.95$ and consider the following geometries: i) Circular with $R / a=3.333$, ii) Elliptic with $R / a=3.333$, and $\kappa=1.5$ and no triangularity, and iii) Dee-shape with $R / a=3.333$, and $\kappa=1.5$ and triangularity, $\delta=0.5$. The numerical values of $q^{\prime}$ and $I(90)$ are given in Table I, where we also consider a case with $q_{\text {edge }}=3.62$ and having the Dee shape specified above. For comparison we also include the base case with $R / a=10$ and circular cross-section.

The table shows that the $q^{\prime}$ required to stabilise the mode incre $\cdots p s$ as the aspect ratio decreases or the non-cicularity increases. At first glance this seems to imply that the circular case is more stable than the Dee shaped 


\begin{tabular}{||c|l|c|l|l||}
\hline \hline \multirow{3}{*}{$q_{\text {edge }}=2.95 \beta=0$} & $R / a$ & Cross-section & $q_{\mathrm{c}}^{\prime}$ & $I(90)$ \\
\cline { 2 - 5 } & 10 & Circle & 4.95 & .02 \\
\cline { 2 - 5 } & 3.333 & Circle & 5.25 & .025 \\
\cline { 2 - 5 } & 3.333 & Ellipse $\kappa=1.5$ & 5.76 & .034 \\
\cline { 2 - 5 } & 3.333 & Dee $\kappa=1.5 \delta=0.5$ & 8.20 & .041 \\
\hline \hline
\end{tabular}

.. Table 1: Stability thresholds for different geometries at $\beta=0$

one. This conclusion is misleading as there is a strong connection between the plasma shape and $q^{\prime}$. It is more relevant to look at the $I(90)$ at which the instability occurs. We find that increasing the non-circularity increases the threshold $I(90)$ at which the kink mode is first observed. This is consistent with the generally accepted view that Dee shaped plasmas are more stable than circular plasmas.

\section{Finite $\beta$}

The study of the current driven external kink mode at finite $\beta$ is complicated by several factors. The principal difficulty lies in seperating the roles of the current and pressure profiles, which are interconnected. One common technique is to switch to the study of flux-conserving equilibria where the $q$ and $p$ profiles are specified independently as oppcsed to specifying $g$ and $p$. The problem with this approach is that as $\beta$ is increased the current profile rapidly distorts and it is impossible to control the details of the profle as was done in the zero $\beta$ case. The alternative is to stick with the $p, g$ method for specifying the plasma profiles. This method is more difficult since it requires a constant adjustment of the $g$-profile as $\beta$ is increased to keep the global parameters, $q_{\text {axis }}$ and $q_{\text {edge }}$ approximately constsnt. In any case, care must be taken to avoid pressure driven instabilities, such as the ballooning mode. Furthermore, to emphasize the role of the pressure, it would be desirable to choose the profiles so that the $\beta$ threshold is fairly high. This requires profiles with sufficient shear to make the zero $\beta$ case stable.

We return in the large aspect ratio, $R / a=10$, circular cross-section equilibrium model. The profiles arc adjusted so that $q_{\text {edge }} \simeq 2.9$ and $q_{\text {axis }} \simeq$ 1.05. The pressure profile is chosen to be fairly broad and is given by,

$$
p=\eta_{\circ}\left\{(1-\Psi)^{2}+p_{1} \Psi^{4}(1-\Psi)\right\}
$$


and

$$
p^{\prime}=-p_{\circ} 2(1-\Psi)+p_{1}\left(\Psi^{4}-4 \Psi^{3}(1-\Psi)\right) .
$$

This functional form permits us to selectively increase the pressure gradient, $p^{\prime}$, near the edge by raising $p_{1}$. Initially $p_{1}$ is set to zero and the $\beta$-limit is determined by varying $p_{\mathrm{o}}$ and determining the stability . Each time $p_{\mathrm{o}}$ is varied, the coefficients of the $g$-function are adjusted to obtain the desired $q_{\text {axis }}$ and $q_{\text {edge. }}$. As observed in figure 10 . the $\beta$ limit is, $\beta=1.85 I /(a B) \Leftarrow$ for this sequence. Note that the Troyon limit for this case would be $\beta=$ $3.5 I /(a B)$ and would be reached if the pressure profile had been optimized. We then choose a case with a lower $\beta(=1.27 I /(a B))$ for the base case. This is well below the stability threshold for the pressure driven mode in this equilibrium, so that a current-driven instability can be observed. We now increase $p_{1}$ slowly and determine the stability of this sequence. The choice of the pressure profile function is such that increasing $p_{1}$ has a minimal effect on $\beta$. In the range of this study, $\beta$ rises from 1.270 to $1.274 I /(a B)$. The effect on the stability is however quite pronounced as an external kink mode is destabilized, the eigenfunction is similar to that shown in figure 2. A plot of the growth-rate as a function of $p_{1}$ is shown in Figure 11. This shows clearly $\Leftarrow$ that the mode is not driven by the pressure but by the current profile. To connect this with the earlier results, we plot the edge-current parameters and $q^{\prime}$ versus $p_{1}$ in Figurs 12 and 13 respectively. These figures show that as $p_{1}$ is increased $I(90), / ; J_{\text {edge }} / J_{a x i s}$ increase and $q^{\prime}$ decreases. The reduced shear drives an instability similar to that observed in the zero pressure case.

It should be noted here that this study of the role of pressure on the kink mode is not comprehensive. It is only meant to show that the kink mode can be destabilized by a build-up of current density through an enhanced pressure gradient near the plasma edge. The plasma pressure can also contribute to the destabilization in other ways. For example at high $\beta$ the ballooning terms in $\delta W$ will have a negative contribution, which can lower the threshold for the instability. When this happens the mode structure is no longer dominated by the high- $m$ component near the plasma edge and has large contributions from other poloidal harmonics inside the plasma, as shown in figure 4 . Other possibilities, not shown here, include; a coupling to the internal kink, $m / n=$ $1 / 1$, mode or to the infernal modes. 


\section{Discussion}

In this study we have shown that the stability of the external kink mode is determined by a combination of; $q_{\text {edge }}$, the shear, $q_{\text {edge }}^{\prime}$, the current density at the plasma edge, $J_{u d g e} / J_{a x i s}$, the current in the vicinity of the plasma edge, $I(90)$, and the plasma $\beta$. In particular we note that shear is the principal stabilizing mechanism for the external kink mode. We also find that it is dependent on $I(90)$. The shear required to stabilize the mode, $q_{c}$, depends on $J_{\text {edge }} / J_{a x i s}$ and $\Delta q$. Increasing $J_{\text {edge }} / J_{\text {axis }}$ increases the required shear to stabilize the mode. At $\beta=0$ there is a similar corelation between $q_{c}^{\prime}$ and $\Delta q$. At finite $\beta$ the situation is complicated by the possibilty of a synergistic effect where the balloning term in $\delta W$ helps to lower the threshold for instability. In finite $\beta$ equilibria the unstable mode structure can be similar to the currentdriven peeling mode confined to the plasma edge, or can have a broader radial extent coupling strongly to other poloidal harmonics which are large in the plasma interior. It is interesting to note that in this case the mode structure may have an anti-balllooning nature, i.e., have a larger value on the high field side of the major axis, in the region of good curvature.

We propose that the ELMs are a manifestation of external kinks in tokomak plasmas. When a plasma enters the $\mathrm{H}$-mode its confinement improves and it builds up a finite current density near the edge. When this exceeds a threshold it triggers the instability. Depending on the plasma conditions, the instability may either be localised near the edge and is observed as grassy- or single- ELMs; or the instability couples into the plasma interior and appears as a giant-ELM . A natural extension of this scenario would suggest that if the plasma is close to its ballooning limit, the instability could also result in a disruption which may or may not terminate the discharge. In most ELMs the instability has the effect of reducing the current density near the plasma edge thereby restoring a stable equilibrium. The cycle then repeats itself, the frequency of repetition would be a function of the plasma transport near the edge, which will determine the rate at which the current density can build up again.

The dependence of the kink mode stability on the current density near the plasma edge admits some other intriguing possibilities. The most obvious is the potential for controlling or mitigating the effect of ELMs by lowering the current near the edge through negative current drive. The improved 
stability to kinks with lower current density may hold the explanation for the improved quality of shots in current ramp-down experiments, where the ramp down has the effect of preferentially shedding current near the plasma edge. In terms of total MHD stability, current driven kinks are just one of the factors to be considered. Sawteeth, balloning and resistive modes also play significant roles and it should be recognized that these instabilites are not independent as they are all driven by similar forces, and at high- $\beta$ it becomes difficult to seperate them.

Several secondary topics arise which are beyond the scope of this paper, but may be germane to the $\mathrm{H}$-mode regime and the appearance of ELMs. We briefly address them, and caution the reader that for the moment these are speculative remarks. The role of plasma resistivity is an important issue. The ideal kink modes have resistive counterparts which may have lower thresholds in terms of temperature and could induce the effects associated with grassy ELMs. They are unlikey to play a role in giant ELMs. Another interesting speculation is that the resistive modes may play a role in determining the plasma confinement. We suggest that during the lower confinement L-mode regime of operation, the lowered edge temperature which implies a more resistive plasma is subject to high $m / n$ resistive kink and/or tearing modes restricted to the plasma edge which enhance the radial transport there. If the temperature rises suddenly, possib!y due to the arrival of a sawtooth heat pulse, the resistivity drops and the plasma near the edge behaves as an ideal rather than a resistive plasma. The ideal plasma has good surfaces and improves the confinement causing the $\mathrm{H}$-mode transition. Then the edge current density buids up until it exceeds the threshold for ELMs and the cycle proceeds, as indicated in this paper. Another interesting topic is the role of wall stabilization. The external kink mode can be stabilized by placing a conducting wall close to the plasma. We believe that such a stabilzation will be most effective for grassy ELMs which we believe are mostly current driven peeling modes. The larger ELMs have a large contribution from the ballooning term, and would only be delayed by the walls, unless the wall is virtually at the plasma edge and is perfectly conducting.

Finally we offer a few remarks on the comparison of this model for ELMs with experimental observations. If ELMS are caused by kink modes, we expect that they will have fast growth-rates, comparable to the Alfven time, have a mode structure which peaks at the plasma edge. The poloidal mode 
content would be mixed in most cases and consequently hard to determine, in contrast the toroidal mode number should be unity. The observations on $\mathrm{PBX}-\mathrm{M}^{9}$ support this picture and they also offer clues on the difficulty of interpreting the experimental observations. In particular, it was observed that, the ELM precursor was short lived $(\leq 350 \mu \mathrm{s})$ with a high frequency of $200-250 \mathrm{kHz}$. The precursor grew with a growth time of $10 \mu \mathrm{s}$. These are all features consistent with the kink model for ELMs. They also highlight the difficulty of identifying the MHD activity, which is of brief duration and occurs at a frequency which is high and close to the Nyquist frequency of the instruments. At these frequencies it is difficult to establish the poloidal mode number. Another interesting feature of the observation was that the amplitude was larger on the high field side, a contra-indicator of ballooning modes. We note however that pressure driven kink modes, figure 4 , have such a structure. In light of these observations we believe that kink modes are a credible cause of ELMs in tokamaks.

In this paper we have examined the connection between certain aspects of the plasma profiles near the edge and stability to the external kink mode. Specifically we find that the current density near the plasma edge plays a crucial in determining the stability. Enhanced current density weakens the shear and leads to destabilization of the kink mode. We propose this as the model for ELMs in H-mode plasmas.

\section{A. Acknowledgements}

We take great pleasure in acknowledging many useful discussions with Drs. S. Kaye and J. L. Johnson. This work was supported by DoE contract No. DE-AC02-76-CHO-3073. 


\section{Figures}

Figure 1.

In a zero- $\beta$ circular, $R / a=10$, tokamak plasma, the current profile,(figure 1a), is adjusted to maintain fixed $q_{a x i s} \sim 1.05, q_{\text {edge }}=2.95$ and $J_{\text {edge }} / J_{\text {axis }}=0.058$ for three cases $(a),(b)$ and $(c)$. The corresponding three $q$ profiles are shown in figure $1 \mathrm{~b}$.

Figure 2.

An example of a peeling type of external kink mode in a zero- $\beta$ circular, $R / a=10$, tokamak plasma with $q_{a x i s} \sim 1.05, q_{\text {edge }}=2.95$. Figure $2 \mathrm{a}$ shows the radial dependence of the poloidal fourier harmonics of the instability und figure $2 \mathrm{~b}$ shows a projection of the displacement vector onto the $x-z$ plane.

Figure 3.

An example of an extended type of external kink mode in a zero- $\beta$ circular, $R / a=10$, tokamak plasma with $q_{a x i s} \sim 1.05, q_{\text {edge }}=2.27$. Figure $3 \mathrm{a}$ shows the radial dependence of the poloidal fourier harmonics of the instability and figure $3 \mathrm{~b}$ shows a projection of the displacement vector onto the $x-z$ plane. Note the deeper penetration of the instability when compared with figure 2 .

Figure 4.

An example of a pressure driven external kink mode.in a $\beta=3.4 I /(a B)$, circular, $R / a=10$, tokamak plasma with $q_{a x i s} \sim 1.05, q_{\text {edge }}=2.95$. Figure $4 \mathrm{a}$ shows the radial dependence of the poloidal fourier harmonics of the instability and figure $4 \mathrm{~b}$ shows a projection of the displacement vector onto the $x-z$ plane. Note the larger amplitude on the inboard side.

Figure 5.

The critical shear required to stabilize the external kink mode for three difrerent fixed values of $J_{\text {edge }} / J_{\text {axis }}$.

Figure 6.

At fixed $q_{a x i s} \sim 1.05, q_{e d g e}=2.95$, and zero- $\beta$. The critical shear required to stabilize the external kink mode increases as the edge current density rises. 
Figure 7.

The shear required to stabilize the kink mode at zero- $\beta, q_{\text {crit }}^{\prime}$, increases as $\Delta q$ decreases. At finite $\beta$ the pressure distribution will modify this dependence.

Figure 8.

The current concentrated within the last $10 \%$ of the plasma is a good measure of the shear, $q^{\prime}$. The scatter is due to the mix of edge current conditions. If all other quantities, e.g., $q_{a x i s}, q_{e d g e}, J_{e d g e} / J_{a x i s}$ and $\beta$ are held fixed a simple linear relationship is observed.

Figure 9.

The threshold edge current to drive the zero- $\beta$ kink mode depends $q_{e d g e}$. Instability occurs when $I(90)$ exceeds the indicated value for different values of $q_{e d g e}$. At finite $\beta$ these curves will also depend on the pressure distibution.

Figure 10.

Choice of a base case to study local current density effects at finite $\beta$. To avoid the usual pressure driven instability, we select a case with a $\beta$ approximately $30 \%$ below the threshold in terms of the Troyon factor ,$g \equiv \beta /(I / a B)$.

Figure 11.

Destabilization of a peeling type of kink mode by raising the pressure gradient, $p^{\prime}$, near the plasma edge.

Figure 12.

The change in $I(90)$ and $J_{\text {edge }} / J_{a x i s}$ as $p^{\prime}$ is increased near the edge.

Figure 13.

The shear at the plasma edge, $q^{\prime}$, is reduced by increasing $p^{\prime}$ near the edge. 


\section{References}

${ }^{1}$ Wagner, F., Becker, G., Behringer, K. et. al. in Plasma physics and Controlled Nuclear Fusion Research 1982(Proc. 9th Int. Conf. Baltimore, 1982) Vul. 1, IAEA Vienna (1983) 43.

${ }^{2}$ Kaye, S., Bell, M., Bol, K., et. al. J. Nucl. Mater. 121 (1984) 115

${ }^{3}$ Odajima, K., et. al., in Plasma Physocs and Controlled Nuclear Fusion Research 1986 (Proc. 11th Int. Conf. Kyoto, 1986), Vol. 1, IAEA, Vienna (1987) 151.

${ }^{4}$ Burrell et. al. Phys. Rev. Lett., 59 (1987) 1432.

${ }^{5} \mathrm{JET}$ Team, in Plasma Physics and Controlled Nuclear Fusion Research 1988 (Proc. 12th Int. Conf. Nice, 1988), Vol. 1 IAEA, Vienna (1989) 159.

${ }^{6}$ Bush et. al. , Phys. Rev. Lett. 65 (1990) 424.

${ }^{7}$ P. Gohil et. al., Phys. Rev. Lett. 61 (1988) 1603.

${ }^{8}$ N. Ohyabu et. al. Nucl Fusion 29 (1989) 475.

${ }^{9}$ S. M. Kaye, N. Asakura, B. LeBlanc, C. Kessel, Y. T. Lau, J. Manickam, S. Paul, and S. in Nuc. Fusion 30 (1990) 2621.

${ }^{10} \mathrm{MHD}$ activity during ELMs, S. von Goeler, O. Klüber, G. Fußman, J. Gernhardt and M. Kornherr, in 30 (1990) 395.Nuclear Fusion.

${ }^{11}$ Observation of Precursor Magnetic Oscillations to the $H$-Mode transition of the ASDEX Tokamak, K. Toi, J. Gernhardt,O. Klüber and M. Kornherr in Phy. Rev. Lett. 62 (1989) 430-433.

${ }^{12}$ Toroidal effects on magnetohydordynamic modes in tokamaks, E. A. Frieman, J. M. Greene, J. L. Johnson, and K. E. Weimer, Phys. of Fluids, 16 (1973) 1108-1125.

${ }^{13}$ R. C. Grimm, J. M. Greene and J. L. Johnson in Methods of Comp. Phys. 16 (1975) 273. 


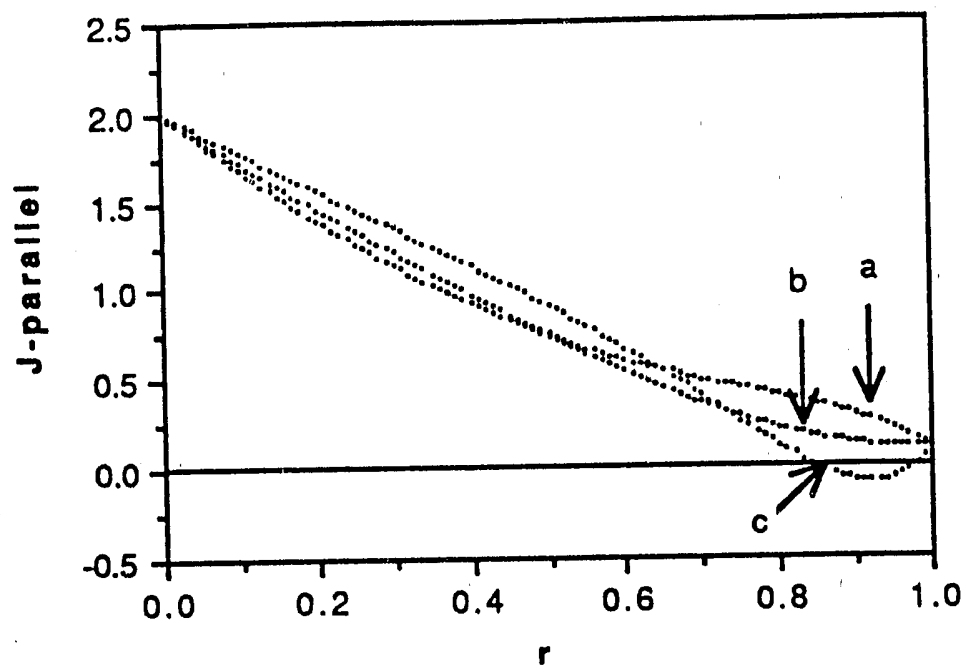

Fig. 1a

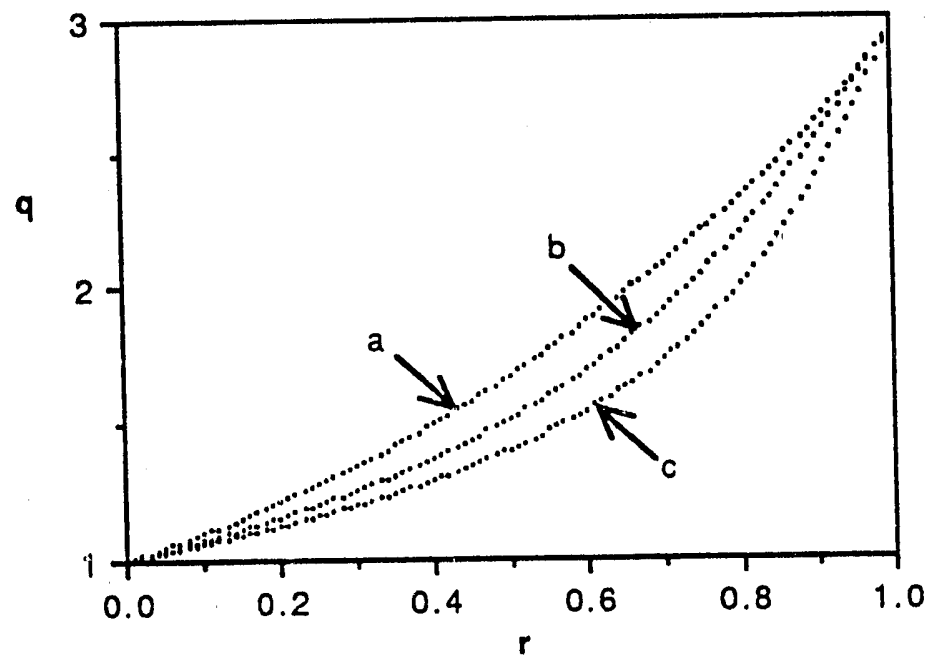

Fig. 1b 


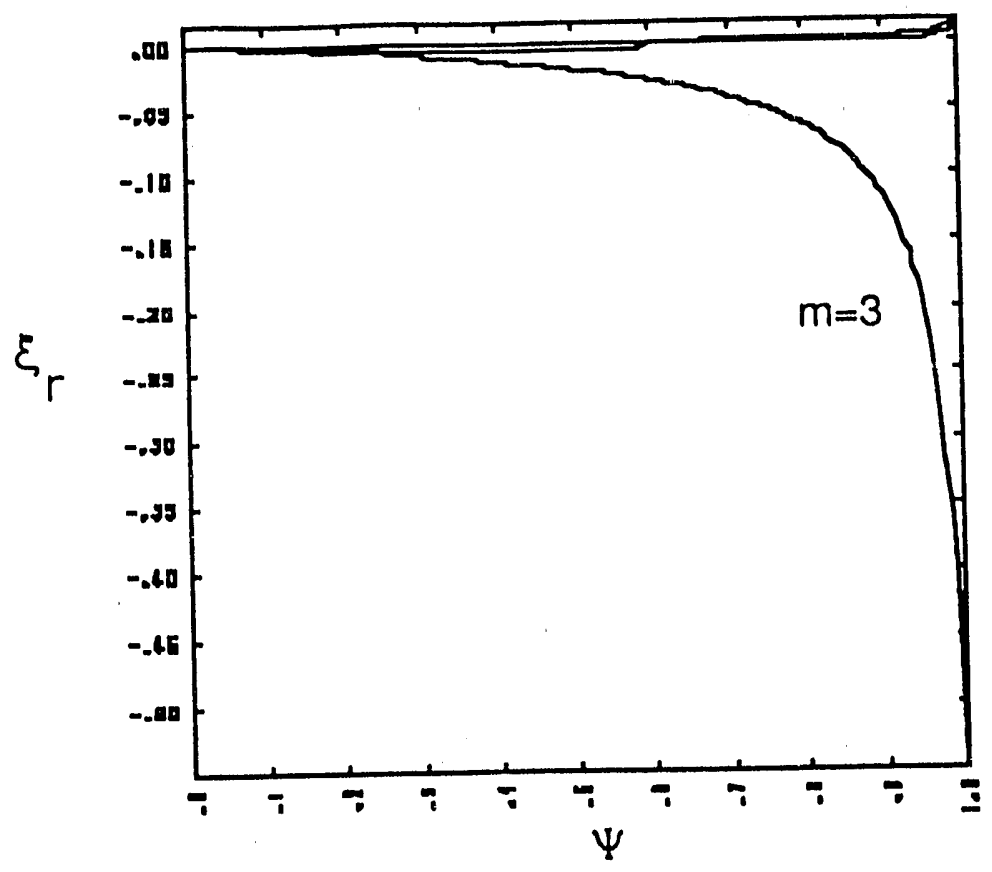

Figure $2 a$

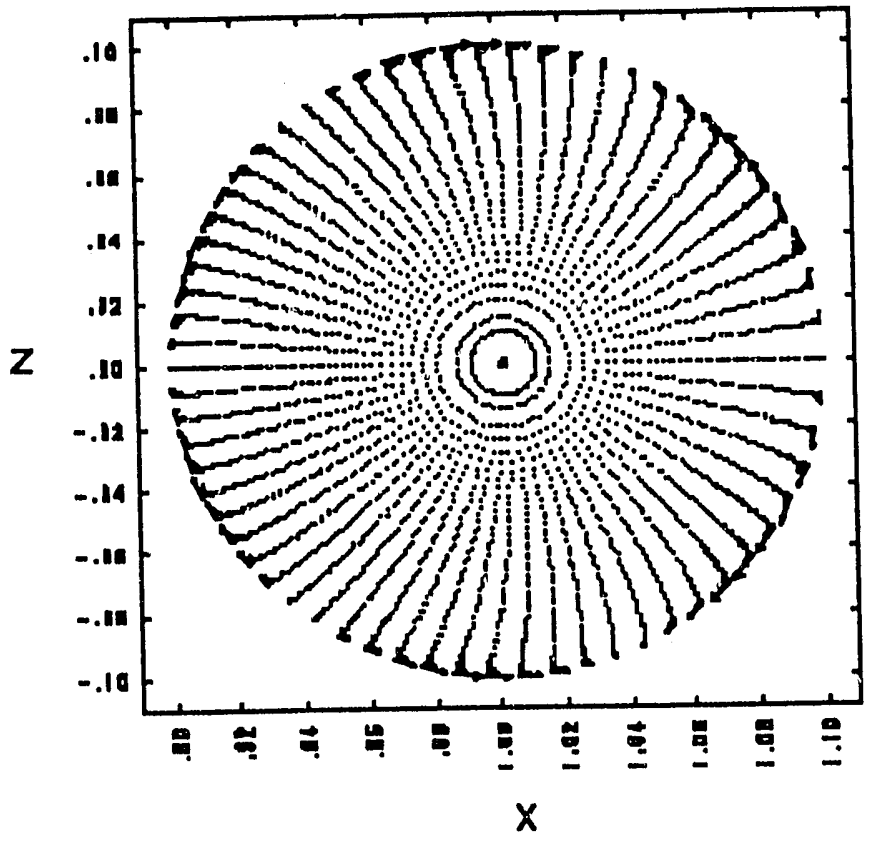

Figure 2b 


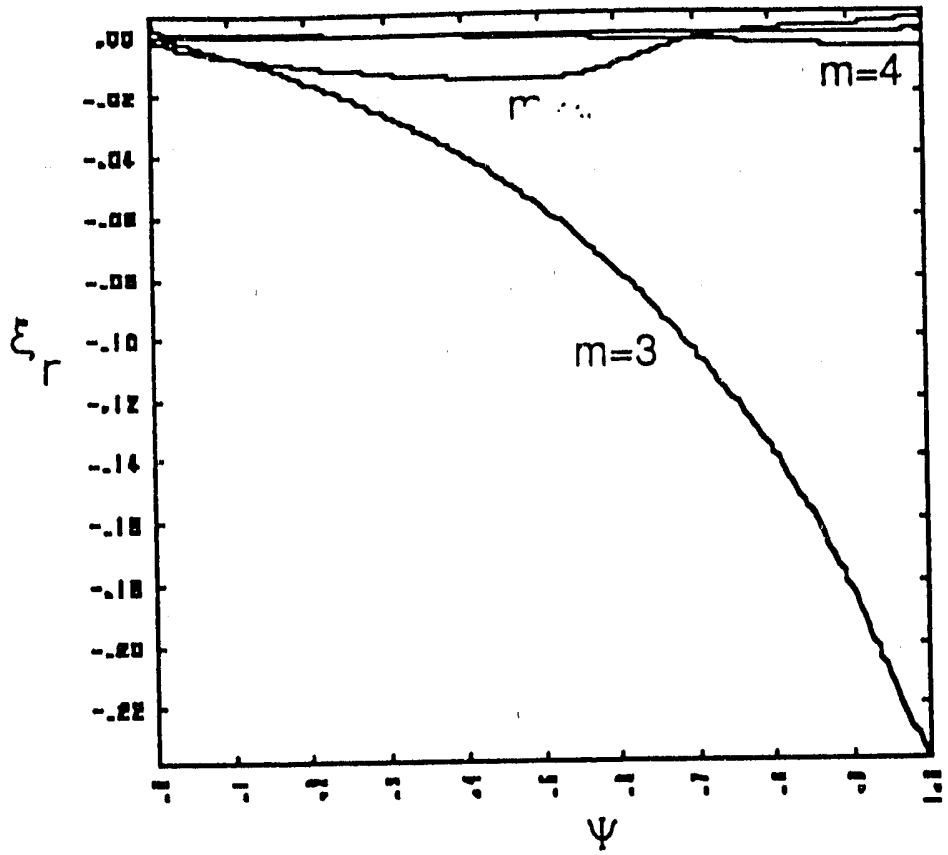

Figure $3 a$

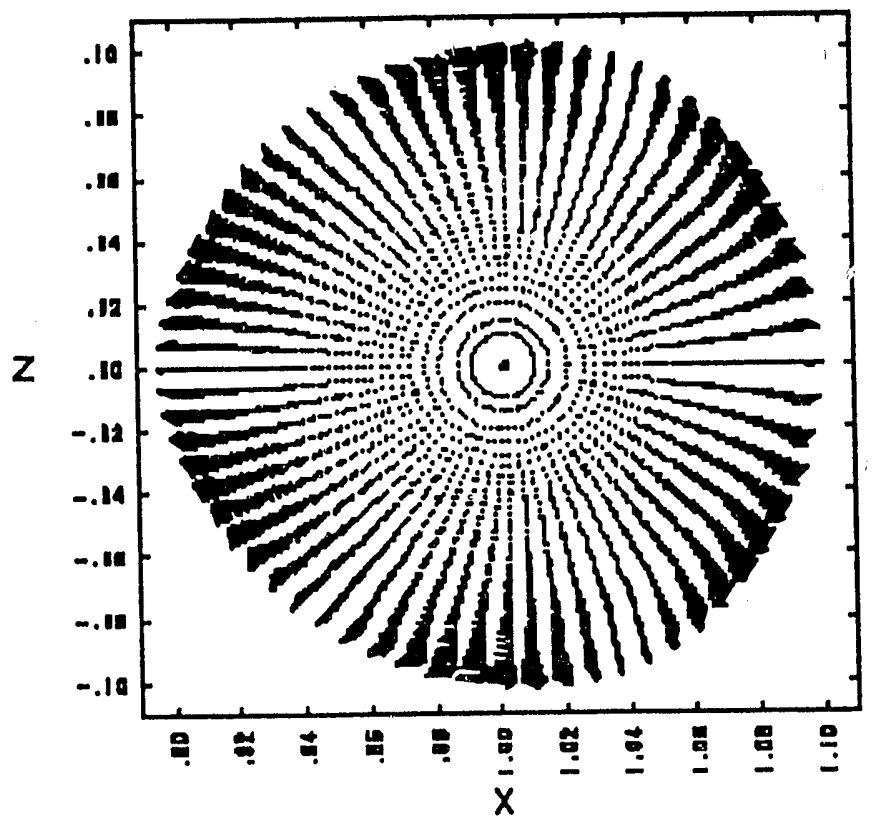

Figure 3b 


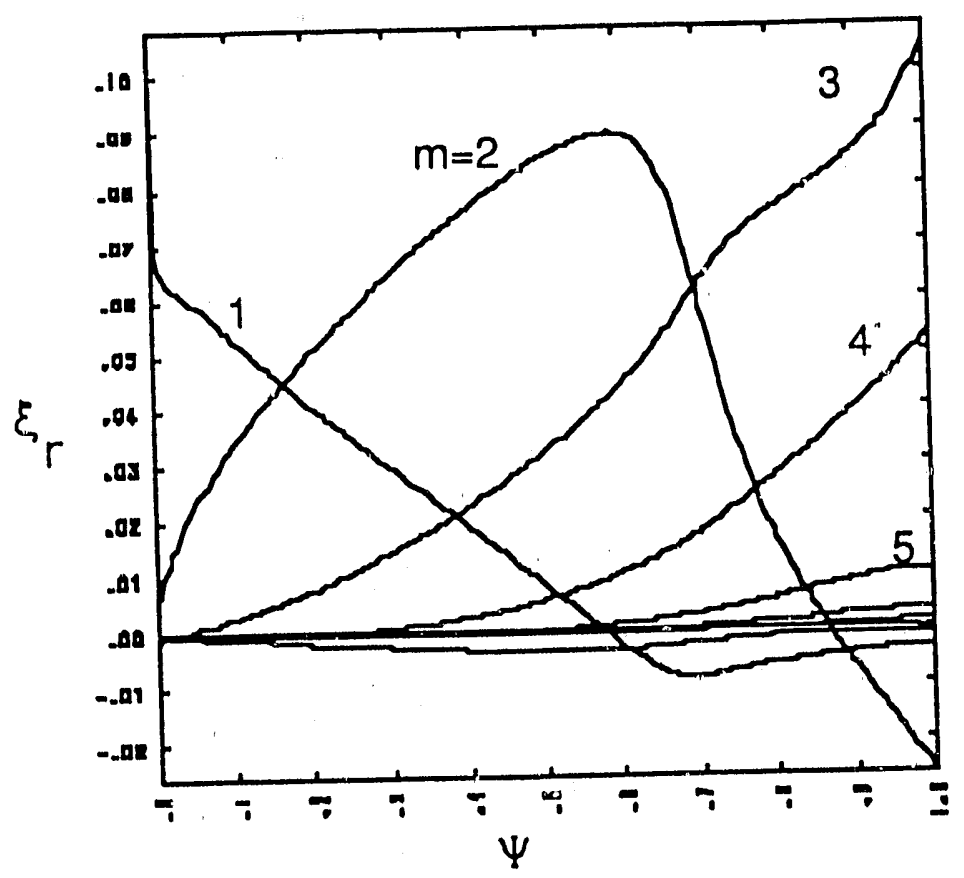

Figure $4 a$

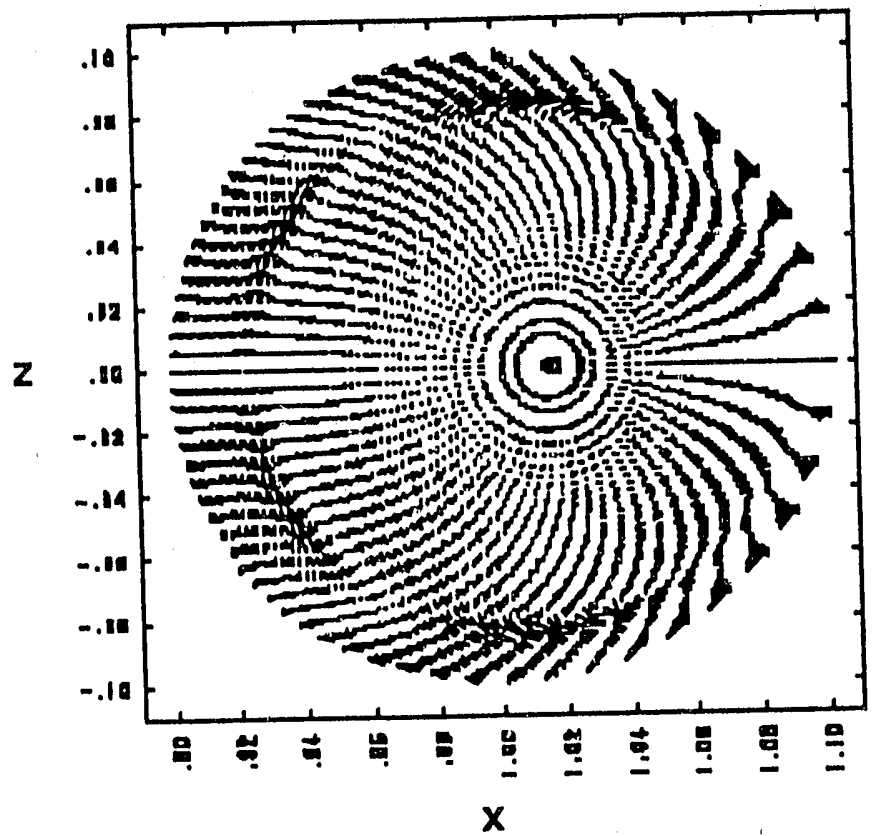

Figure $4 b$ 

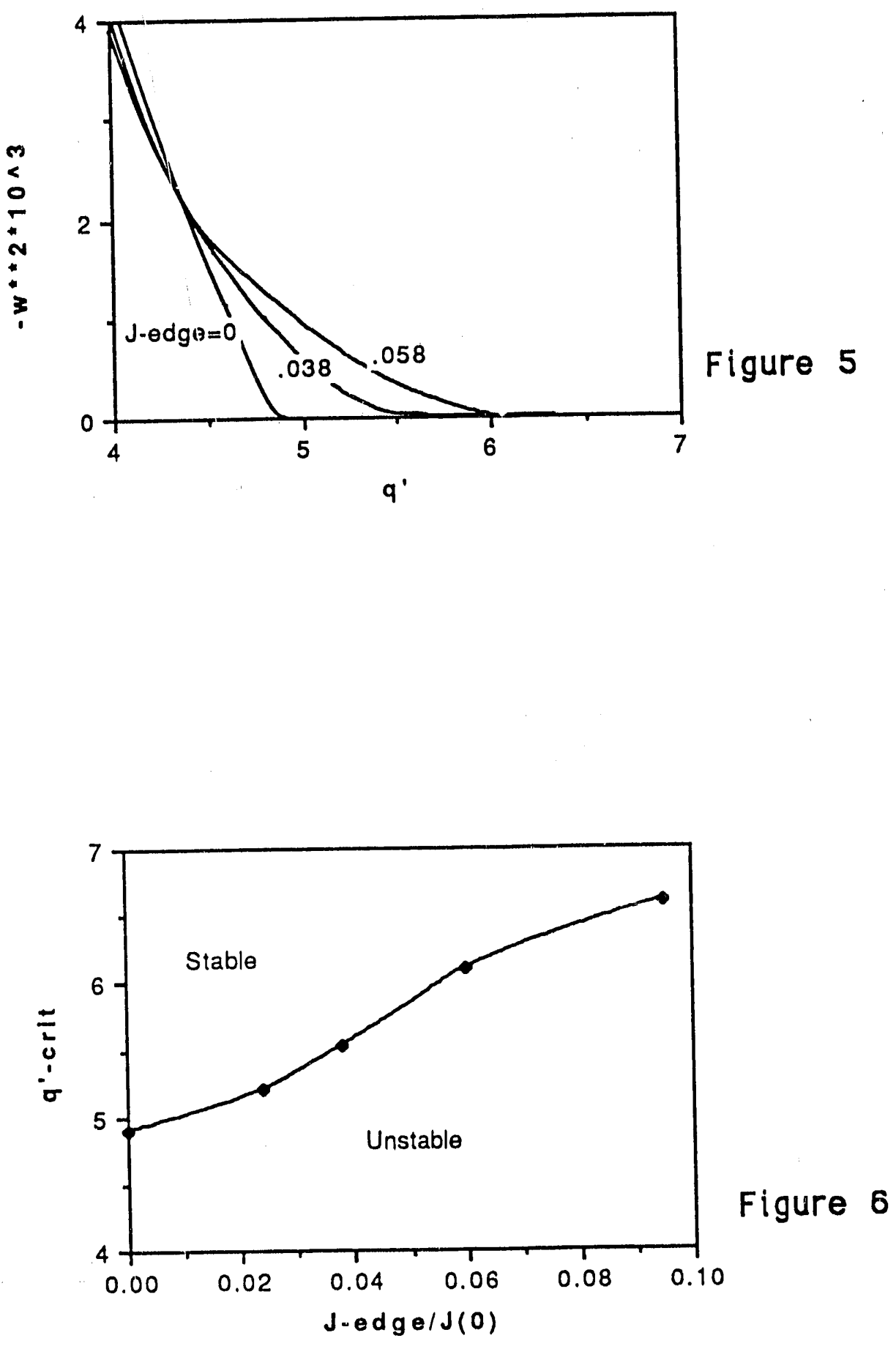


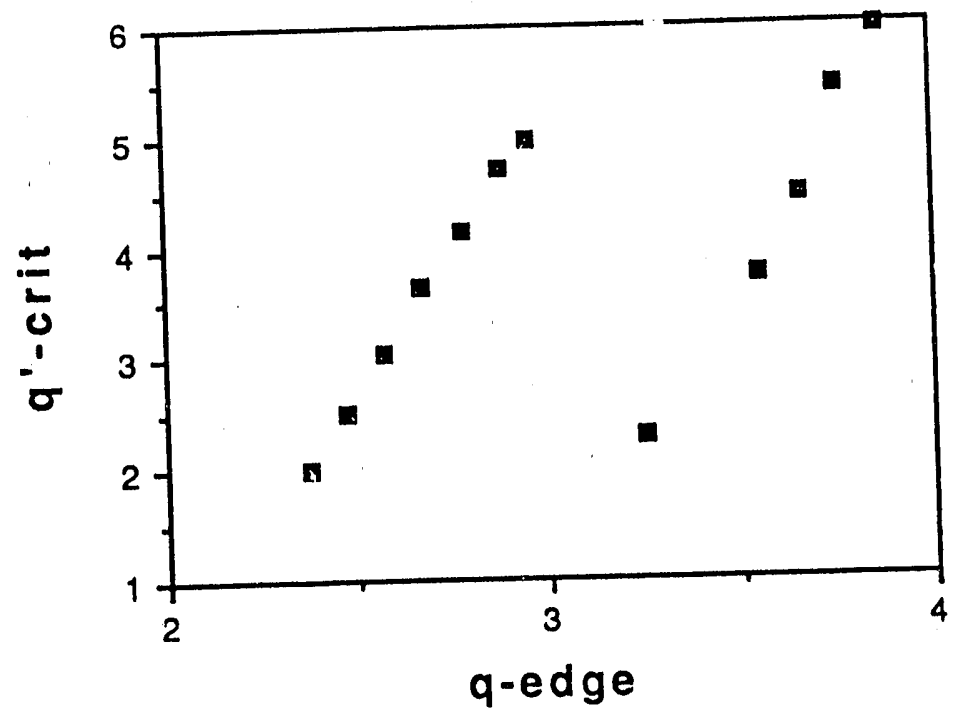

Figure 7

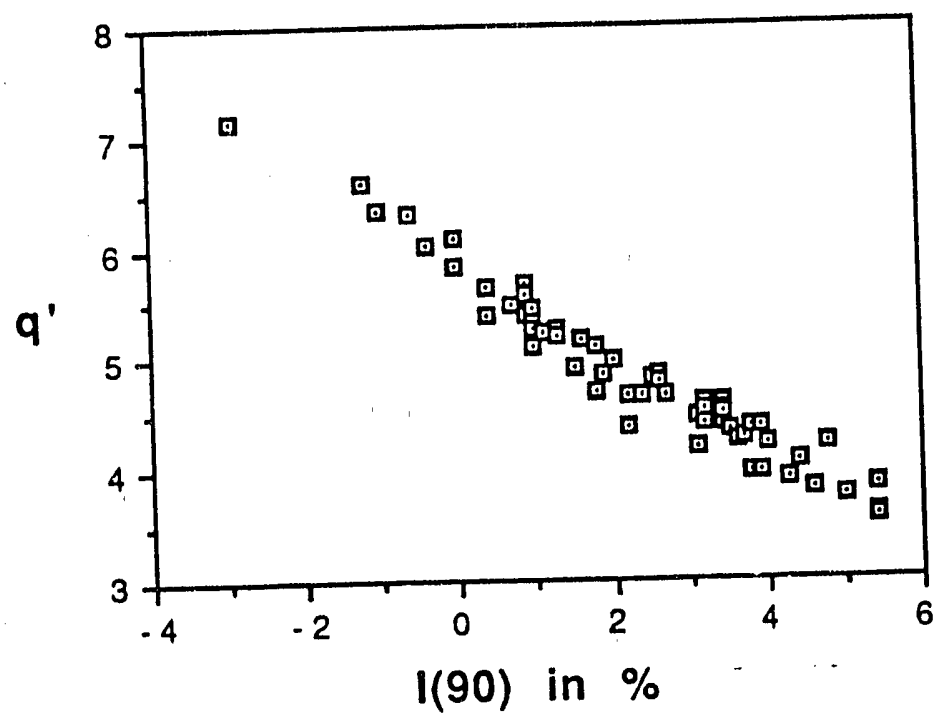

Figure 8 


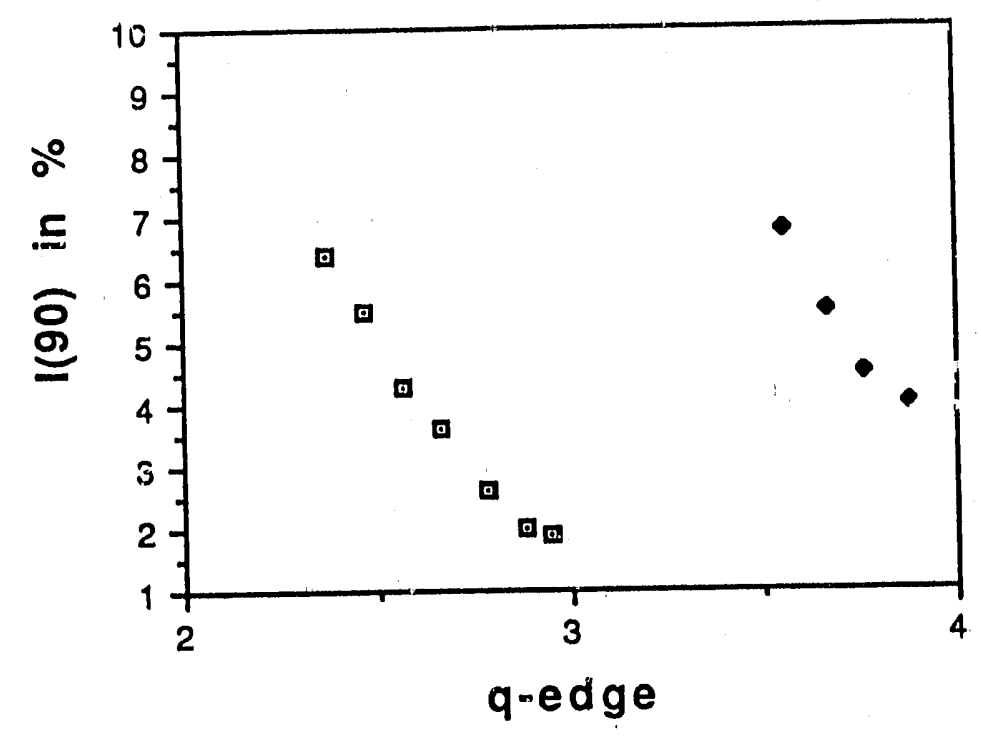

Figure 9

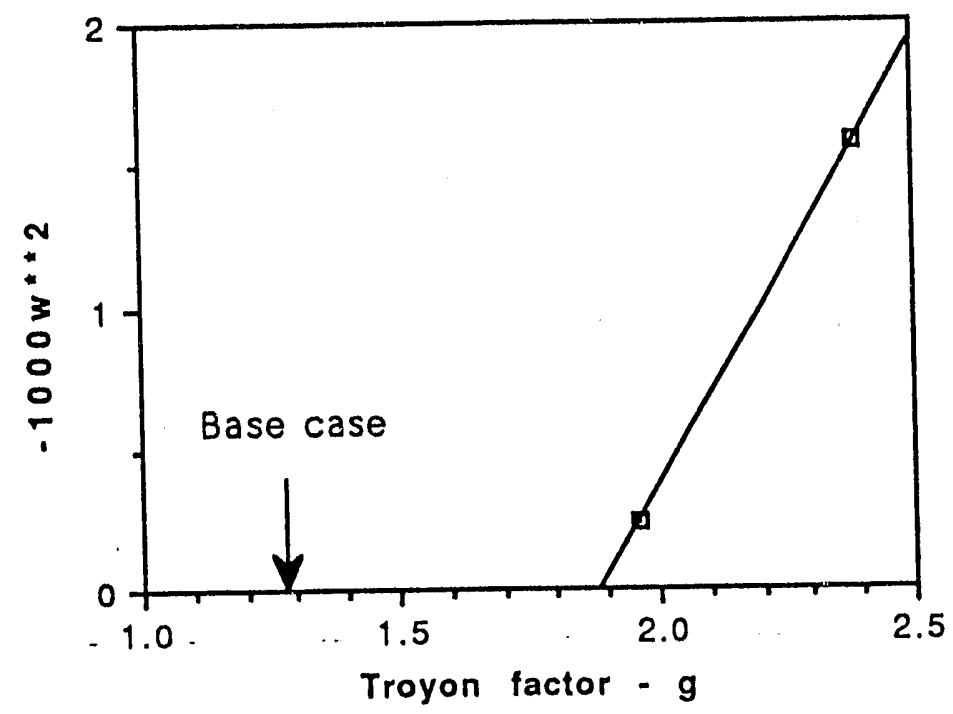

Figure 10 


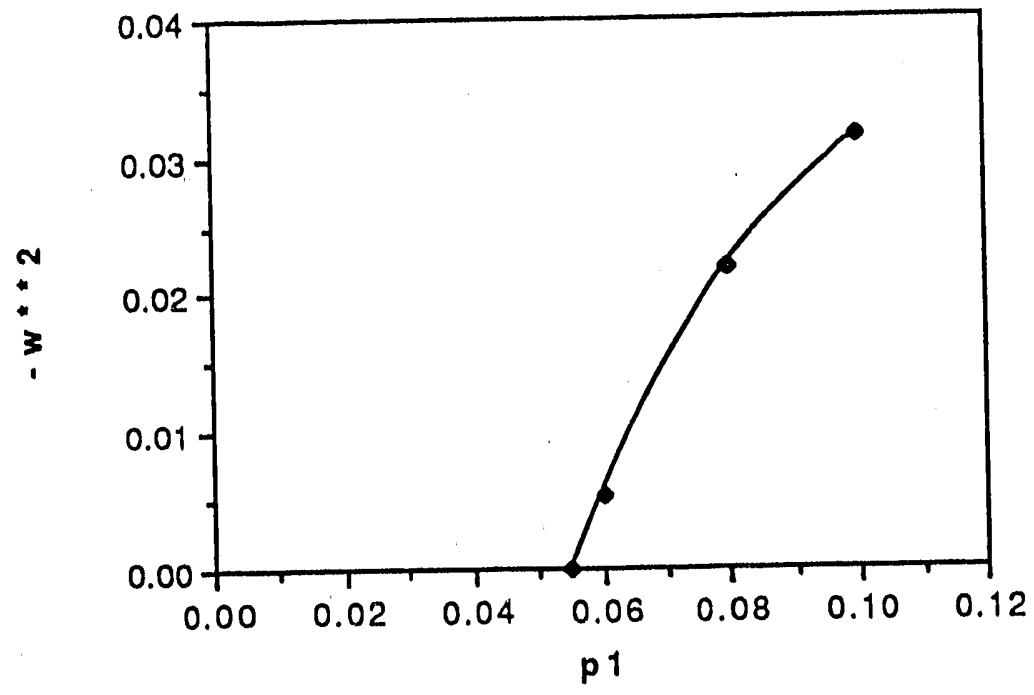

Figure 11

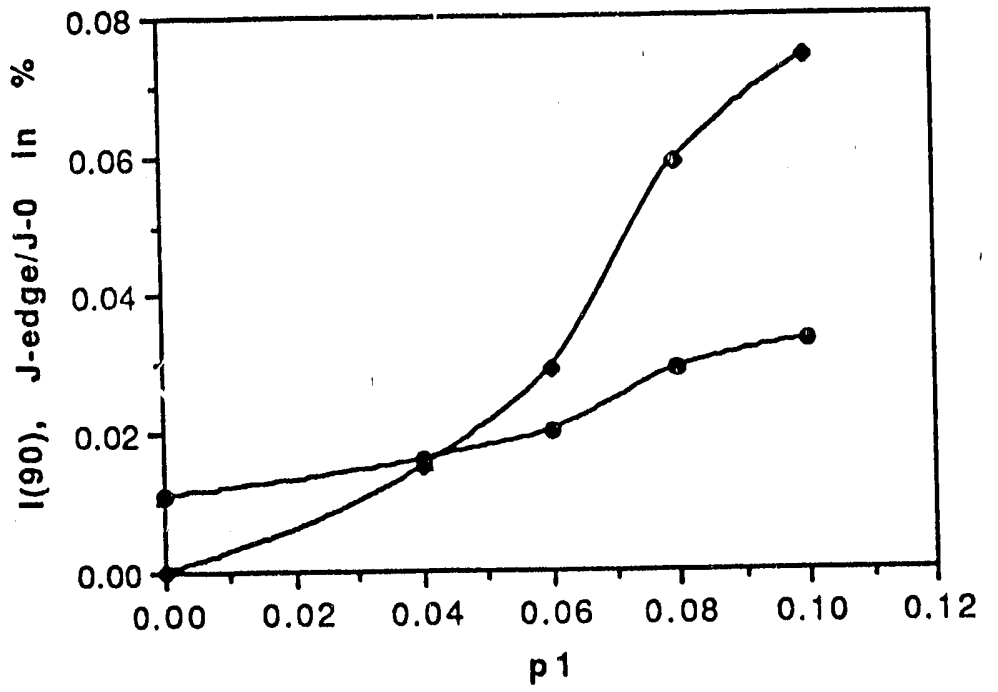

- $J>90 \%$

- J-edge/J-zero

Figure 12

i 


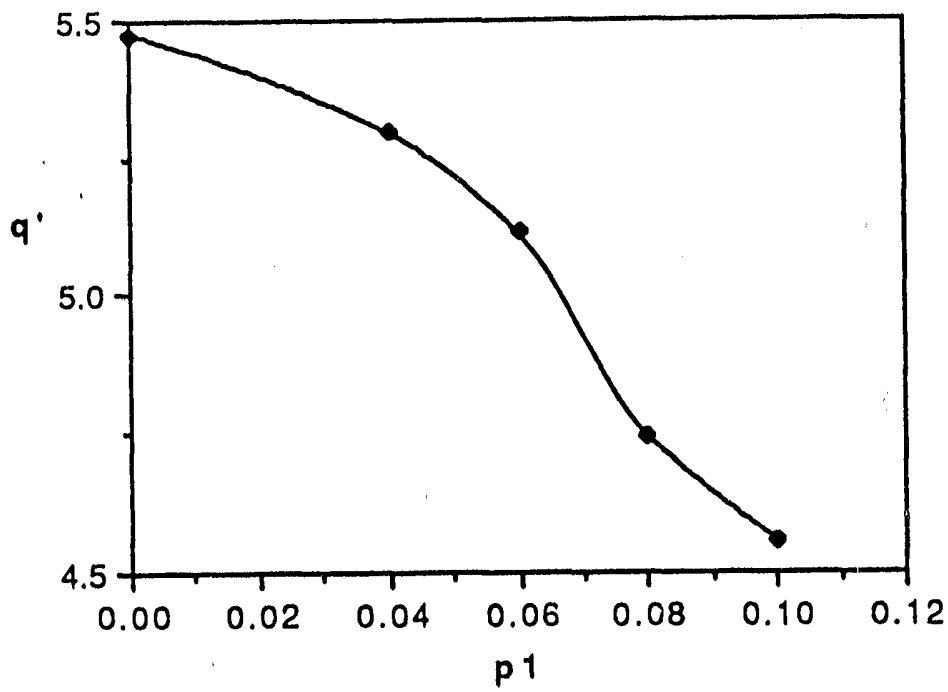

Figure 13 
Dr. F. Paokoni, Univ. of Wollongong, AUSTRALIA

Prof. M.H. Brennan, Univ. of Sydney, AUSTRALIA

Plasma Research Lab., Australien Nat. Univ., AUSTRALIA

Prof. I.R. Jones, Flinders Univ, AUSTRALIA

Prof. F. Cap, Inst for Theoretical Physics, AUSTRIA

Prof. M. Heindier, Instibut for Theoretische Physik, AUSTRIA

Prof. M. Goossens, Astronomisch InstituUt, BELGIUM

Ecoiv Roydo Mitivirs, Lb. do Phy. Plasmas, BELGIUM

Commicsion-Europeen, DG. XII-Fusion Prog., BELGIUM

Prof. R. Bouciqud, Rikeuniveratit Gent, BELGIUM

Dr. P.H. Sakenaka, Instituso Fiaica, BPUZIL

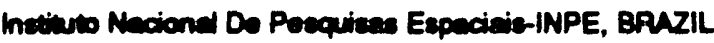

Documents Ofiros, Alomic Enorgy of Ceneda Lid., CANADA

Dr. M.P. Bechyndti, MPB Technologies, Inc., CANADA

Dr. H.M. Skaregard, Univ. of Sackatchowen, CANADA

Prof. J. Teichmann, Univ. of Montreal, CANADA

Prof. S.R. Sreeniveaen, Univ. of Cobary, CANADA

Prof. T.W. Johneton, INRS-Energio, CANADA

Dr. R. Botton, Contre canedien do tusion magnstique, CANADA

Dr. C.R. James, Univ. of Aberta, CANADA

Dr. P. Lukta, Komenaktho Univarazita, CZECHO-SLOVAKIA

The Librarian, Culhem Laboratory, ENGLAND

Librery, R61, Ruthertond Appleton Laboratory, ENGLAND

Mrs. S.A. Hutchincon, JET Librey, ENGLAND

Dr. S.C. Sheme, Univ. of South Pacific, FWII ISLANDS

P. Mahonen, Univ. of Heloinkj, FINLAND

Prof. M.N. Buseace, Ecole Polybachnique., FRANCE

C. Moutrat, Lab. de Physiquo des Milioux lonisés, FPANCE

J. Radoh, CENVCADARACHE - Bat 506, FRANCE

Prof. E. Economou, Univ. of Crow, GREECE

Ms. C. Rinni, Univ. of loemnina, GREECE

Dr. T. Mud, Acadermy Bibliographic Ser., HONG KONG

Preprint Librery, Hungarian Acadomy of Sa., HUNGAAY

Dr. B. DasGupta, Saha Inst of Nuclaer Physics, INDIA

Dr. P. Kaw, Inst. for Plasma Posearch, INDIA

Dr. P. Pocenew, lereed Inst of Technology, ISPAEL

Librarian, intornationd Conter for Theo Physics, ITALY

Miss C. De Palo, Associazione EURATOMENEA, ITALY

Dr. G. Groseo, Istituro di Fisica del Plasma, ITALY

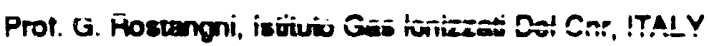

Dr. H. Yamato, Toshiba Res a Devel Center, JAPAN
Prof. I. Kawakami, Hiroshima Univ., JAPAN

Prof. K. Nishikawa, Hiroshima Univ., JAPAN

Director, Japen Atomic Energy Rosearch Inst., JAPAN

Prof. S. Itoh, Kyustu Univ., JAPAN

Research Info. Ctr., National Instit. for Fusion Science, JAPAN

Prot. S. Tanaka, Kyoto Univ., JAPAN

Librey, Kyow Univ., JAPAN

Prof. N. Inowe, Univ, of Tokyo, JAPAN

Socretary, Plesma Section, Electrotochnical Lab., JAPAN

S. Mori, Techniced Advieor, JAERI, JAPAN

Dr. O. Miturai, Kumamoso Inst of Technology, JAPAN

J. Hyeon-Sook, Korea Alomic Enorgy Research Inst., KOREA

D.I. Choi, The Korea Adv. Inst. of Sai. Tech., KOREA

Prof. 8.S. Liby, Univ. of Waikab, NEW ZEALAND

Inst of Physics, Chinese Acad Sa PEOPLE'S REP. OF CHINA Library, Inst. of Plasma Physics, PEOPLE'S REP. OF CHINA Tainghua Univ. Library, PEOPLE'S REPUBLIC OF CHINA Z. Li, S.W. Inat Physica, PEOPLE'S REPUBUC OF CHINA Prof. J.A.C. Cobrai, Instiuto Superior Tecnico, PORTUGAL Dr. O. Potrus, Al I CUZA Univ., ROMANIA

Dr. J. do Viliers, Fusion Studies, AEC, S. AFRICA

Prof. M.A. Hellberg, Univ. of Natal, S. AFRICA

Prof. D.E. Kim, Pohang Inst. of Sci. \& Tech., SO. KOREA

Prof. C.I.E.M.A.T, Fusion Division Library, SPAIN

Dr. L Simflo, Univ. of UMEA, SWEDEN

Librery, Royal inst. of Tectnology, SWEDEN

Prof. it. Witholmson, Chelmers Univ. of Tech., SWEDEN Contre Phys. Des Plasmas, Ecole Polytech, SWITZERLAND Bibliotheek, Inst. Voor Plasma-Fysice, THE NETHERLANDS Asst. Prof. Dr. S. Cakir, Midde East Tech. Univ., TURKEY Dr. V.A. Gukthith, Sci. Mes. Inst. Electrophys.I Apparatus, USSR Dr. D.D. Ayutov, Siberian Branch o. Academy of Sci., USSR Dr. G.A. Eliseov, I.V. Kurchatov Inst, USSR Librarien, The Ukr.SSA Academy of Scionces, USSR Dr. LM. Kovizinmykh, Inst. of General Physics, USSR Kemforectungsanlegge GmbH, Zentralbibliothek, W. GERMANY Bibliothok, Inst. For Plasmaforschung, W. GERMANY Prof. K. Schindler, Ruhr-Universitát Bochum, W. GERMANY Dr. F. Wagner, (ASOEX), Max-Planck-Institut, W. GERMANY Librarian. Max-Plonck-Institut, W. GERMANY

Prof. P.K. Janev, Inst, of Physics, YUGOSLAVIA 

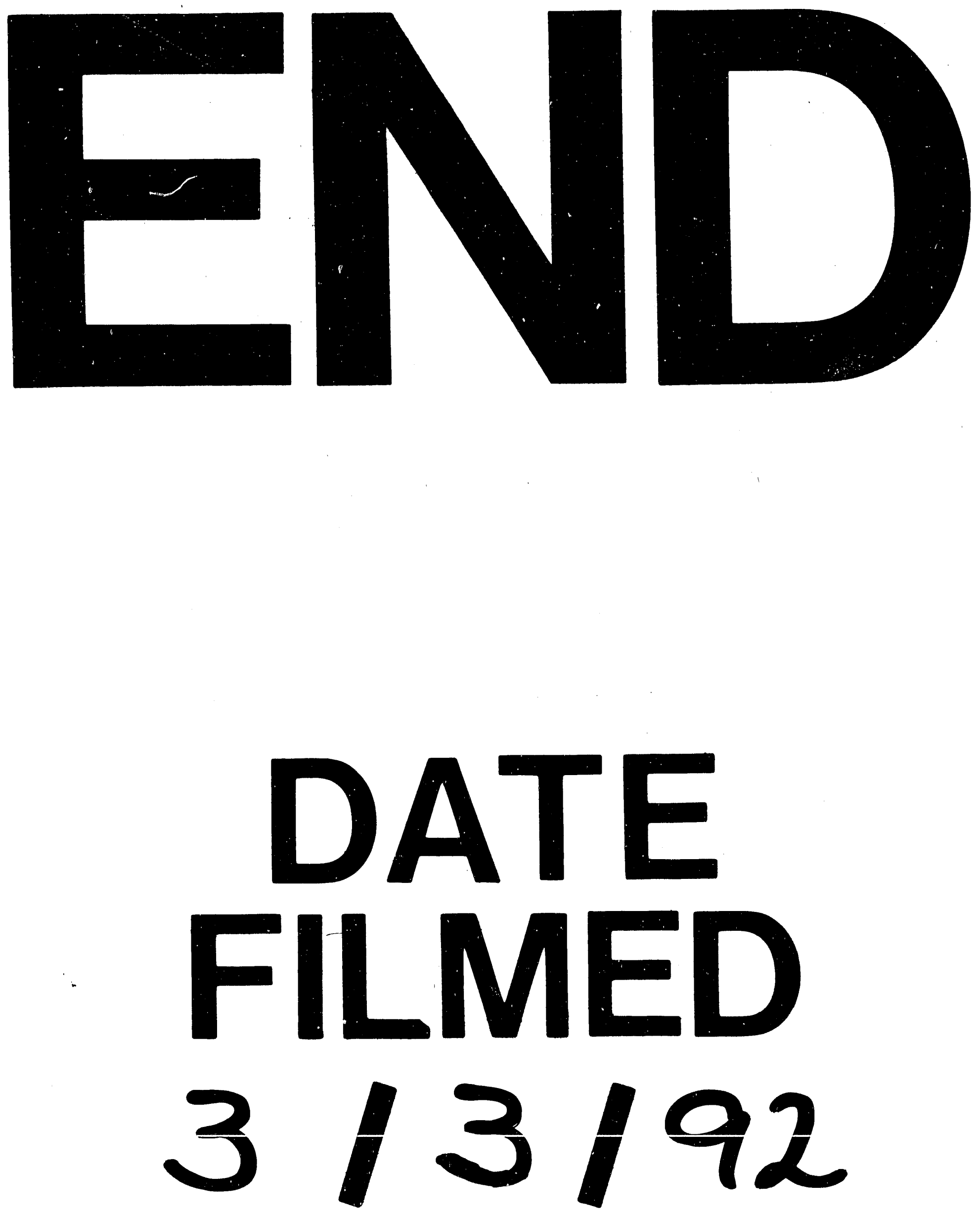

I 
